chronographs referred to was a cylinder (or barrel) 12 in. in diameter, and $2 \mathrm{ft}$. $6 \mathrm{in}$. long. That cylinder, which was covered with paper, rotated once in two minutes Beneath it (see Fig. I) was a pricker placed in electrical connection with the standard clock, and alongside another pricker placed in electrical communication with in observer at any of the instruments. At every second of the standard clock, the clock pricker rose and punctured the paper. Meanwhile, as the cylinder rotated, the carriage, $\mathrm{K}$, on which the prickers were mounted slowly, travelled along the length of the cylinder ; and this motion of $\mathrm{K}$, combined with the rotation of the cylinder, caused the succession of clock pricks to arrange themselves around the cylinder in the form of a spiral. The time of any observation was reckoned by comparing the puncture

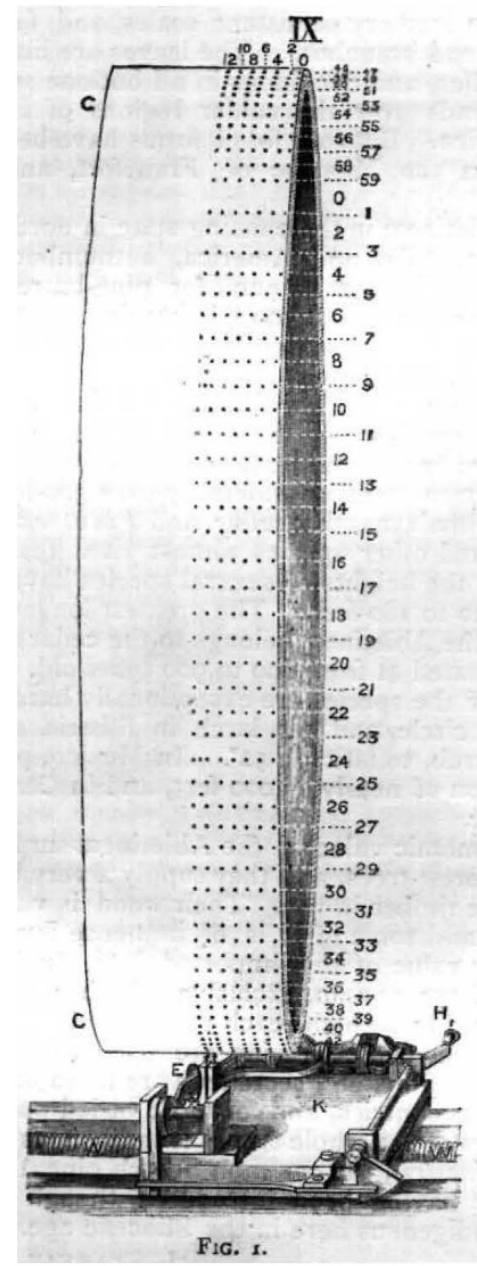

of the observation pricker with the two adjacent clock pricks. The distance between each successive turn of the spiral of clock pricks was $\frac{3}{8}$ inches, and it was within this space (which was limited by the consideration of the size of the cylinder, and the number of hours of observation it should contain) that the two prickers worked.

In the Brussels chronograph, by the directions of M. Houzeau, the Belgian Astronomer-Royal, provision had to be made for three observation prickers, in addition to the clock-pricker. The space available for the prickers to work in was only $\frac{1}{6}$ in., and it was obviously impossible to place them side by side. The difficulty was surmounted by arranging them in the form of a fan, so that they should converge into the space, which then became amply sufficient for the disposition of the punctures.
$\mathrm{N}_{1}, \mathrm{~N}_{2}, \mathrm{~N}_{3}, \mathrm{~N}_{4}$ (see Fig. 2), are the prickers. As may be seen, they take the form of pins with very large heads. Each is mounted in a sheath, SS. Each sheath is jointed (see side section), and swings about an axis A A. It is kept to its bearing by a spring. This arrangement allows the pricker to swing forward a little as it enters the moving paper. It corresponds to the action of the old form of pricker shown in Fig. 3. The pricker, however, that we are describing has an important advantage.

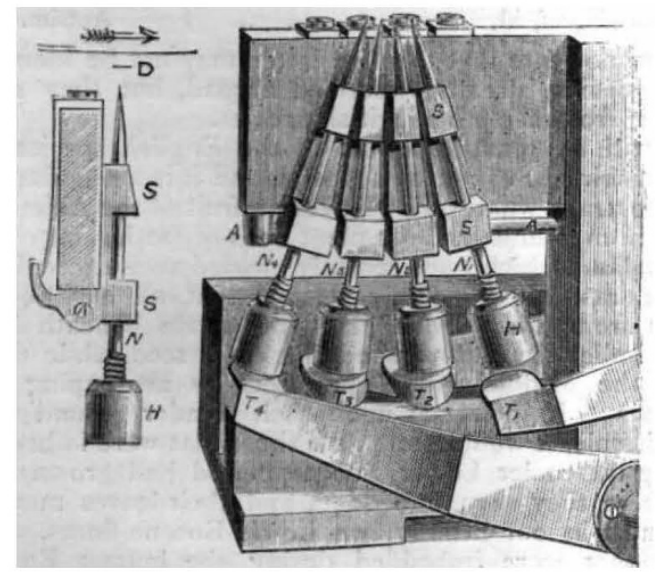

It might happen that an observer on pressing down the electric button which worked the pricker, would keep his finger on it. In that case, with the old form, the pricker would be kept against the paper, and would very likely cause damage. But in the new case nothing of the kind would happen, for each pricker, $\mathrm{N}_{1}, \mathrm{~N}_{2}, \mathrm{~N}_{3}, \mathrm{~N}_{4}$, is projected by the blow of its corresponding striker, $T_{1}, T_{2}, T_{3}, T_{4}$, and travelling beyond the reach of the striker, pierces the paper by its own momentum only. On falling back,

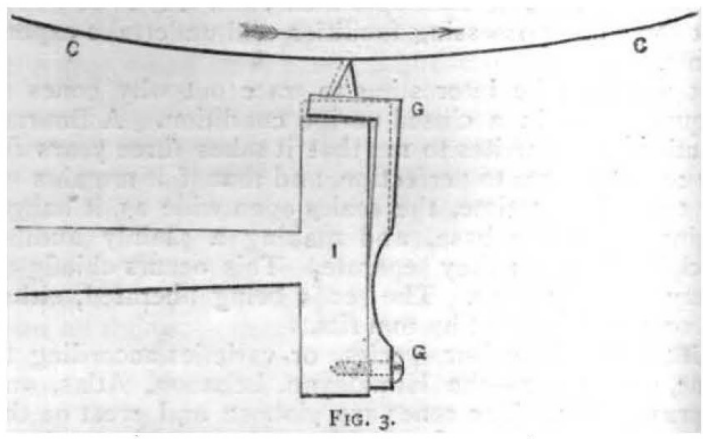

should the striker, $\mathrm{T}$, be still kept raised, the pricker will rest upon it, but its point will be free of the cylinder, and at some distance, $D$, below it. The strikers, $T_{1}$, \&c., are worked by electro-magnets : the spiral spring shown just above the head of each pricker, is compressed when the pricker is projected between the head and sheath, and assists in the disengagement of the pricker from the paper. The punctures of the prickers are very marked and distinct.

\section{A NON-ELECTRIC INCANDESCENT LAMP}

A BRIGHT light, easily obtained and sufficient for projections, bas frequently been regarded as a desideratum, where it has been impracticable to procure either the electrir or the lime-light. The French Minister of Public Instruction lately appointed a special commission to indicate the apparatus most suitable for projection in primary schools; and it appeared that while there was no lack of simple arrangements for the projection proper, 
the problem of easy production of an adequate luminous source was hardly solved.

Dr. Regnard has lately conceived the idea of getting a bright light by burning on platinum gauze a mixture of air and petroleum vapour. The intense heat which results raises the platinum to bright incanciescence, giving a light equal to about half the lime-light.

The apparatus (described in La Nature, to which we are indebted for the accompanying figure) is very simple. There is an ordinary Bunsen burner, terminated by a small cage of platinum wire. The mixture of air and petroleum vapour is admitted below, in place of the gas; it is produced by a familiar method, and the current is generated by means of a pair of bellows or a Richardson "pear." With a ventilator or "trompe," several of the lamps may be maintained in action at once, for lighting halls, workshops, \&c., where there is no gas. The aspect

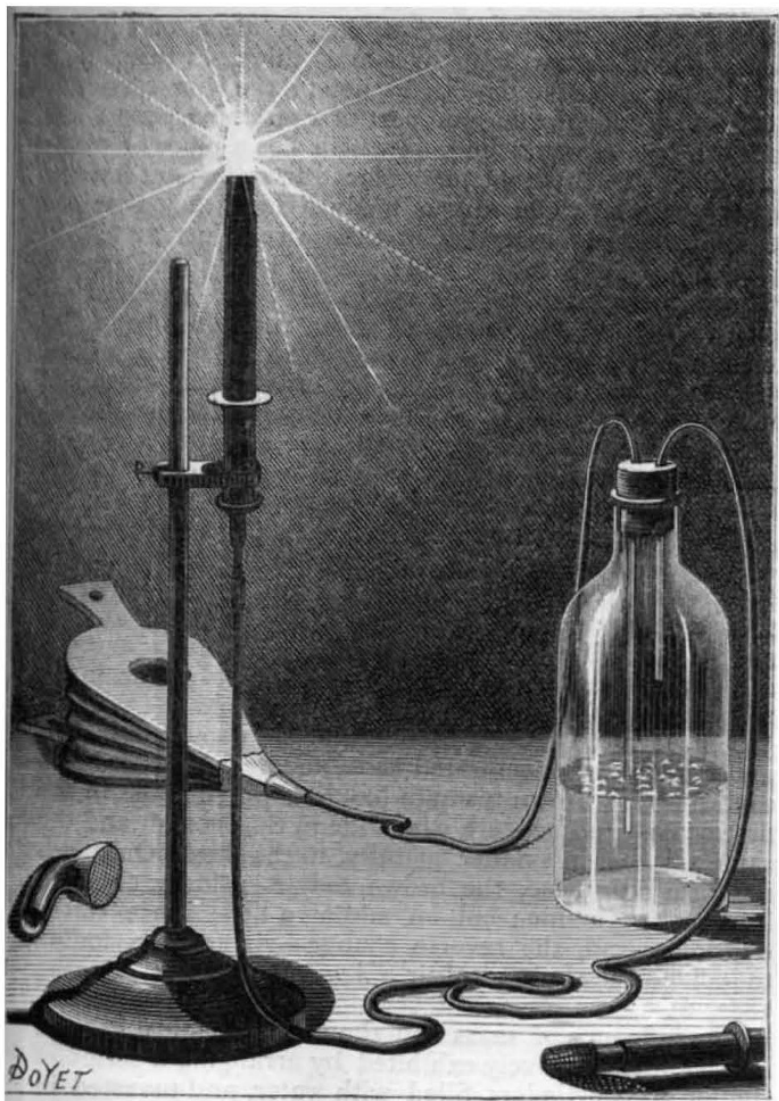

Regnard's Incandescent Lamp.

is that of electric incandescent lamps. In this case, it is well to augment the volume of the carbonator, so that the supply of petroleum vapour is abundant. To send all the light in one direction, the Bunsen burner may be fitted with a bent trumpet-shaped nozzle closed with platinum gauze. One has merely to regulate, with the ring of the burner, the admission of the mixture of air and vapour, to have, whenever the current is produced, an extremely bright light.

With a large loaded bag of air under the table the lamp may be kept in action for several hours, without requiring attention.

The apparatus should be useful to medical men in examination of the larynx, ear, \&c.

The expenditure is very small, only a few centimes an hour, with maximum action.
OBSERVATIONS OF THE SOLAR ECLIPSE OF 1882, MAY I6, MADE AT THE RADCLIFFE OBSERVATORY, OXFORD

$T \mathrm{HE}$ weather was very favourable, the sky being quite clear.

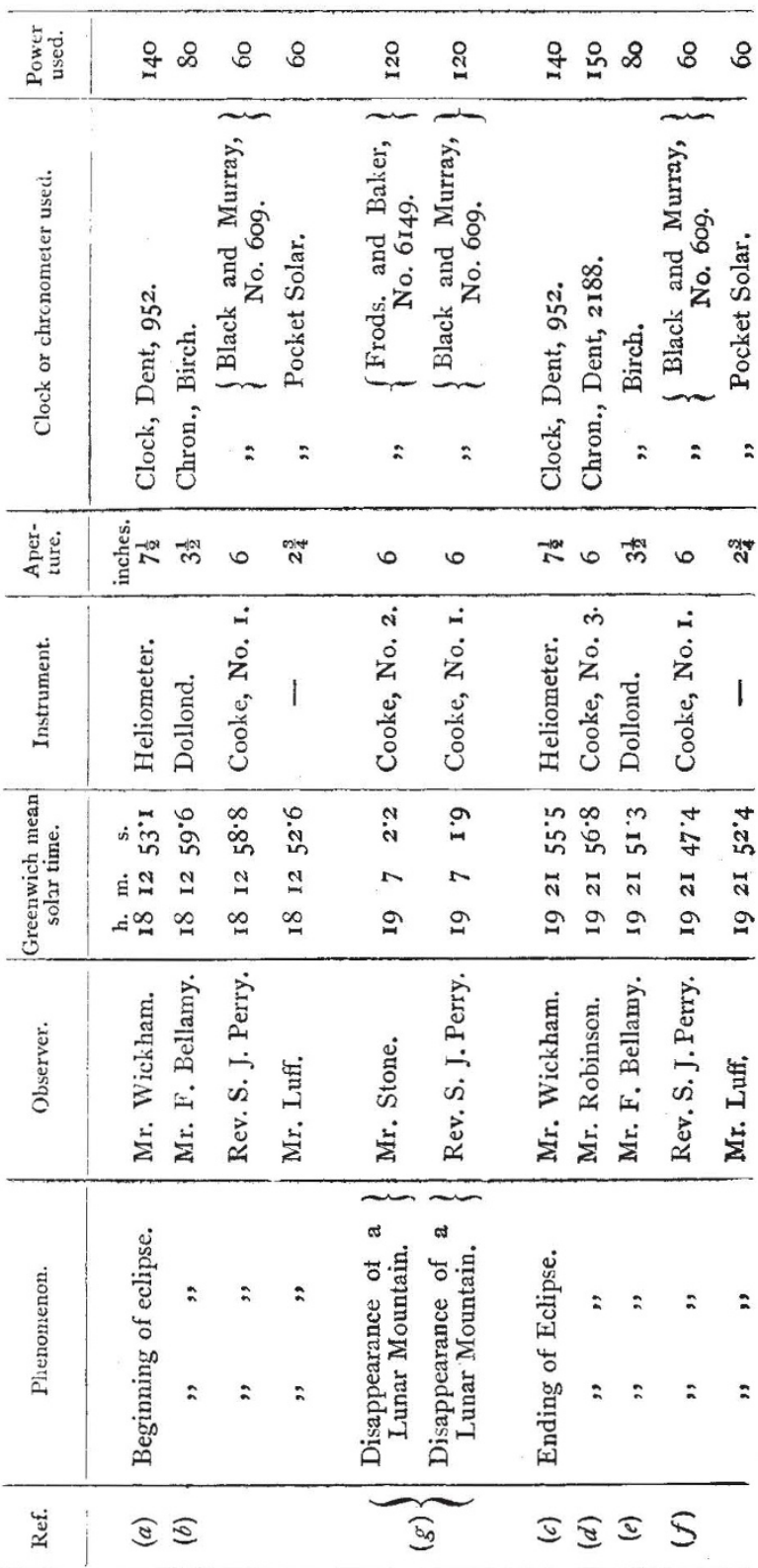

Remarks.-(a) The first contact was detected as the merest trace of an indentation on the sun's limb, and the time recorded is considered precise. (b) Limbs very steady; the time noted may be a very little late. (c) The recorded time of last contact considered accurate, as the moon's limb was followed steadily till the last. The tremor of the sun's limb did not very materially affect the definition. (d) Just before contact limbs slightly tremulous; observation considered fairly good. (e) Observation good. $(f)$ If anything a fraction of a second too soon.

$(g)$ This mountain was the highest peak of a ridge of mountains which were conspicuous on the moon's limb. E. J. STONE 